\title{
Nurses and their Ongoing Engagement in Nursing Research: A Brief Commentary
}

\section{Suzanne Fredericks}

Daphne Cockwell School of Nursing, Ryerson University, 350 Victoria St. Toronto, ON; M5B 2K3, Canada

"Corresponding author: Suzanne Fredericks, Daphne Cockwell School of Nursing, Ryerson University, 350 Victoria St. Toronto, ON; M5B 2K3, Canada, Tel: 416-979-5000 ext. 7978; Fax: 416-979-5332; E-mail: sfrederi@ryerson.ca

Received date: April 8, 2014; Accepted date: April 21, 2014; Published date: April 29, 2014

Citation: Suzanne (2014) Nurses and their Ongoing Engagement in Nursing Research: A Brief Commentary. J Nurs Care 3:155. doi:10.4172/2167-1168.1000155.

Copyright: @ 2014 Suzanne, et al. This is an open-access article distributed under the terms of the creative commons attribution license, which permits unrestricted use, distribution, and reproduction in any medium, provided the original author and source are credited.

\section{Commentary}

This brief commentary is in response to the article titled: Engaging clinicians in research: Issues to consider [1]. The article presented an overview of nursing research that included the various definitions of nursing research, a synopsis of the paradigms associated with nursing research, and a brief presentation of how nurses can engage in research.

Engaging in research is more than just producing evidence. It involves the active seeking out, critiquing, and application of research in the clinical setting. Many clinicians do not have the skills to be able to adequately read or interpret empirical evidence. I would argue that before a clinician can consider designing and implementing a study, they should have a solid understanding of the relationships between research and knowledge and theory and practice.

A solid understanding comes from both education and experience. Education with research principles alone does not make an individual a good researcher. Experience provides the logic as well as the skills to be able to read and interpret data. However, experience does not come at once, rather through incremental exposure and time. Thus, the individual should have an appreciation of the various components of the research process, be able to interpret and evaluate research studies, consider applying empirical findings to their practice, and/or have the ability to identify areas for further investigation. An understanding of the role of ethics and the various considerations that need to be addressed when engaging in research should also be at the forefront of any researcher's repertoire [2].

As a faculty member, who has served as a thesis supervisor to a number of nursing graduate students, and who has taught graduate research courses for the past 7 years, it has become apparent that many nurses are either not prepared or do not have the time to adequately engage in the research process. Many nurses are juggling heavy workloads, work long hour, and have shift work commitments; resulting in minimal opportunities for learning, applying new knowledge, or even reflecting on the day's events or activities. In order to be an effective researcher, one has to have the time to be able to identify issues/problems that need to be addressed. Not all nurses are expected to be involved in research, though they should have the ability to engage to some degree in the scientific critique process. Among those nurses who are actively engaged in research, it should be expected that these individuals receive support in the form of protected time. Critical reflection, review of relevant literature, and having a holistic understanding of the issue is needed to be able to design and conduct a study aimed at addressing the issue. These skills are acquired over time. Nurses need to be motivated to want to engage in these skills and to continue to refine their abilities in this area. Resources in the form of workshops, seminars, research mentors, and reduced workload are needed to support these individuals. Without these sources of support, the entity that is nursing research will remain stagnate.

\section{References}

1. Dunning $\mathrm{T}$ (2013). Engaging clinicians in research: Issues to consider. Nursing \& Care 2(2): 1-3.

2. Ciccone MM, Aquilino A, Cortese F, Scicchitano P, Sassara M, et al. (2010). Feasibility and effectiveness of a disease and care management model in the primary health care system for patients with heart failure and diabetes (Project Leonardo). Vascular health and risk management 6: 297. 